\title{
Tactile retention as a function of delay interval and response mode
}

\section{T. H. ANDERSON AND CHARLES K. WEST DEPARTMENT OF EDUCATIONAL PSYCHOLOGY, UNIVERSITY OF ILLINOIS, Urbana, Ill. $6 I 801$}

Forty Ss were tested for retention of a tactile stimulus. No differences were indicated for response mode (recognition or reproduction) or delay for shape. However, there was a retention mode by practice interaction on the shape measure and a retention mode difference on the weight measure.

Retention studies of visual and/or auditory stimuli and responses have generally concluded that higher retention measures are attained on recognition tasks than on reproduction tasks (Luh, 1922; Postman \& Rau, 1957). Generally, this has been supported in both short- and relatively long-term retention measures. Differences in retention measures between recognition and recall are reduced, however, when the number of alternatives in the recognition task are increased (Davis, Sutherland, \& Judd, 1961) and when the recognition alternative difficulty is controlled by increasing the similiarity between the alternatives (Bahrick \& Bahrick, 1964).

Findings based on visual and auditory stimuli may not necessarily be supported in the instance of tactile stimuli. Adams $(1967$, p. 310$)$ has noted the dearth of research in the retention of sensory and response modes other than those modes relevant to verbal behavior.

The purpose of the present study was to investigate (1) possible effects of response mode (reconstruction or recognition) on the accuracy of retention, and (2) possible effects of the retention interval. A third purpose was to investigate the utility of tactile input in the areas of memory, learning, and problem solving.

Subjects

The Ss were 40 juniors and seniors, 21 boys and 19 girls, from a public high school. Ss volunteered to serve in the experiment during their study hall hours and were paid one dollar for their services.

\section{Materials and Procedure}

The commercial product Play-doh was used by the Ss to make tactile responses. Stimulus objects were also made from Play-doh and allowed to dry for approximately $24 \mathrm{~h}$ before experimental use. After drying for this period of time, the objects gained enough rigidity to be handled by Ss without distortion. Upon completion of a trial session the stimulus objects were sealed in an airtight container to delay cracking.

All Ss attended two sessions, one on each of two consecutive days. During Session 1 , each $S$ was blindfolded and instructed to touch an object for $30 \mathrm{sec}$ and to remember it. The stimulus object was a geometric cone measuring $40 \mathrm{~mm}$ high, $30 \mathrm{~mm}$ across the base and weighed $20.7 \mathrm{~g}$.

Ten of the Ss were instructed to take some Play-doh, which had been kneaded and rolled into a long cylinder, by $E$, and reconstruct the stimulus object immediately after touching the object. Ten other Ss were instructed to recognize the stimulus object from among eight similar alternatives. The alternatives measured 20,30, or $40 \mathrm{~mm}$ across the base and were 30,40 , or 50 $\mathrm{mm}$ in height. Each S's hand was placed in the center (about a 12-in. diameter circle) of the randomly positioned objects and he was instructed to touch all of the objects and choose the one he had earlier been instructed to remember.

All Ss returned after a 24-h delay for Session 2 and were blindfolded before any experimentation. The Ss who were tested for immediate retention in session one, were tested again in the same mode, reconstruction or recognition. Ten other Ss were tested in each mode thus giving independent retention measures of the stimulus object as a function of retention mode and delay interval.

The constructed tactile responses were measured and weighed at the end of each day. Size measures were made to the nearest millimeter and weights to the nearest gram.

Results

The data from the retention studies are presented below in Table 1. As noted earlier the stimulus object had a base diameter of $30 \mathrm{~mm}$, was $40 \mathrm{~mm}$ in height and weighed $20.7 \mathrm{~g}$. The shape measure was determined by dividing the base into the height which yielded a shape of 1.33 for the stimulus object.

Analyses of variance were made on measures of shape and weight. There were no differences in the shape of the objects as a function of retention mode or delay interval. When the weight measures were compared there was a significant difference over the retention interval $(F=4.59, d f=1 / 36, p<.05)$. After $24 h$, the objects constructed and recognized were heavier than the immediate measures.

Data were analyzed to show what practice effects, if any, were present. The data array formed a 2 by 2 factorial design (see Table 2). The results, after a 24 -h delay when one group had practiced and the other had not, show that there was a retention mode by practice interaction on the shape measure $(F=4.96, \mathrm{df}=1 / 36, \mathrm{p}=$ $.05)$ and a retention mode difference on the weight measure $(F=$ $4.39, \mathrm{df}=1 / 36, \mathrm{p}<.01$ ).

The weight differences are most likely reflective of retention of size of the object rather than weight since it is unlikely that Ss were particularly weight discriminative. During the experiment there was no evidence that Ss were attending to weight. Several investigations have noted overestimation of size in other sensory modalities (Bruner \& Goodman, 1947; Postman, Bruner, \& McGinnies, 1948). It is interesting to note that while there was no difference in retention mode in shape, there was in size or weight. This latter difference, the greater error for the reconstruction groups, is perhaps due to the fact that the range in size of the potential reconstructed object was more or less limitless. Perhaps the alternatives in the recognition tasks encompassed more of the possible shapes than size, or weight, so that less difference

Table 1

Comparison of Retention Modes

\begin{tabular}{llcccc}
\hline & & \multicolumn{2}{c}{ Reconstruction } & \multicolumn{2}{c}{ Recognition } \\
\hline Retention Delay & & Mean & Variance & Mean & Variance \\
\hline \multirow{4}{*}{ Immediate } & Base & $33.5 \mathrm{~mm}$ & & $27.0 \mathrm{~mm}$ & \\
& Height & $41.4 \mathrm{~mm}$ & & $40.0 \mathrm{~mm}$ & \\
24 hours & Shape & 1.28 & .07 & 1.53 & .15 \\
24 hours & Weight & $23.5 \mathrm{~g}$ & 94.4 & $16.5 \mathrm{~g}$ & 23.0 \\
& & & & & \\
& & $34.6 \mathrm{~mm}$ & & 32.0 & \\
& & $47.0 \mathrm{~mm}$ & & 43.0 & \\
& & 1.47 & & 1.38 & 64.8 \\
\hline
\end{tabular}


Table 2

Comparison of Response Modes and Practice Effect at a One-Day Retention Interval

\begin{tabular}{lccc} 
& & \multicolumn{2}{c}{ Mean } \\
\cline { 3 - 4 } & & Reconstruction & Recognition \\
\hline \multirow{2}{*}{ Practice } & Shape & 1.23 & 1.53 \\
& Weight & 32.8 & 21.50 \\
\multirow{2}{*}{ No Practice } & Shape & 1.47 & 1.35 \\
& Weight & 33.0 & 24.1 \\
\hline
\end{tabular}

emerged for shape or recognition than for size or weight on reconstruction.

One wonders at the source of the differences in measurements of retention between recognition and reproduction observed in previous studies. It may be that, in addition to the variables discussed by Adams (1967), other factors are involved. It may be that some of the difference lies in the qualitatively different skills necessary for discrimination between alternatives and the skills necessary for correct reproduction. Discrimination skills may be different from reproduction skills. It may be that discrimination skills are less difficult to utilize and are better learned by Ss than reproduction skills. For example, wide divergence in skills is apparent when, in testing for recall of long verbal chains, one tests by multiple choice rather than essay examinations. In the essay (reproduction) task, the $S$ is required to use writing and organizing skills, and we are measuring these in addition to retention of the verbal material. It may be that in the tactile tasks in this experiment, less difference exists between recognition and reproduction skills since no difference in response modes was evident for shape.

In any case, the use of tactile stimuli enabled the investigator to observe responses closely and carefully. It would seem that experiments involving various tactile-type tasks may facilitate investigation in memory as well as in other areas.

During this experiment, a variety of other tactile problems was posed to Ss to include similiarity and difference items, analogies, and a progressive matrix. The investigators were interested in the question of whether or not this sensory mode would be utilized in studies in problem solving and whether more objective observations could be made. Generally, the investigators were excited by the possibilities which seem to emerge.

\section{REFERENCES}

ADAMS, J. A. Human memory. New York: McGraw-Hill, 1967.

BAHRICK, H. P., \& BAHRICK, PHYLLIS, O. A reexamination of the interrelations among measures of retention. Quart. J. exp. Psychol., 16, 318-324, 1964.

BRUNER, J. S., \& GOODMAN, C. C. Value and need as organizing factors in perception. J. abnorm. soc. Psychol, 42, 33-44, 1947.

DAVIS, R., SUTHERLAND, N. S., \& JUDD, B. R. Information content in recognition and recall. J. exp. Psychol., 61, 422-429, 1961.

LUH, C. W. The conditions of retention. Psychol Monogr., 1922, 31. (Whole No. 142).

POSTMAN, L., BRUNER, J. S., \& McGINNIES, E. Personal values or selective factors in perception. J. abnorm. soc. Psychol, 43, 142-154, 1948.

POSTMAN, L., \& RAU, LUCY. Retention as a function of the method of measurement. Univ. Calif. Pub. Psych. Berkeley, 1957, 8, 217-270. 